\title{
3. SPACE MISSIONS TO THE MOON AND PLANETS
}

S.K. RUNCORN / Introductory Remarks

N.F. NESS / The Magnetic Field of Mercury

S.K. RUNCORN / Lunar Magnetism

J.A. VAN ALLEN / On the Magnetospheres of Jupiter, Saturn, and Uranus

C.P. FLORENSKY / The Surface of Venus as Revealed by Venera 9 and 10 Probes

W.K. HARTMANN / Cratering of Terrestrial Planets: Brief Review

J.W. FOUNTAIN and T. GEHRELS / Pioneer Images of Jupiter 
INTRODUCTORY REMARKS

S. K. Runcorn

School of Physics, Newcastle-upon-Tyne, U.K.

A successful joint discussion between Commissions 16 and 17 was held on space exploration of the Moon and Planets. The programme was as follows:Magnetic Field of Mercury (N.Ness), Magnetic Field of Mars, Venus and Moon (S.Dolginov), Magnetic Field of the Moon (S.K.Runcorn), Magnetosphere of Jupiter and Saturn (J.van Allen), Veneral Surface Results (K.P. Florensky, B.Napoklonov, U.A.Surkov), Bombardment Histories for Mercury, Mars and the Moon (W.K.Hartmann), Venus Atmosphere Results from Pioneer 10 and 11 (T.Gehrels), Preliminary Results from Viking Mission to Mars (B.A.Smith and S.I.Rasool), Future Planetary Space Missions: USSR (R.Z.Sagdeyev), USA (S.I.Rasool).

Some of the speakers felt that they did not wish to publish an account of their lecture in Highlights as they considered that recent research in their fields had been very extensively published in recent times. The papers published here form a group of particular interest and importance to the astronomical as well as the geophysical community and their publication in Highlights of Astronomy will therefore be widely welcomed as giving a clear indication of the very important new data on the planets which is being obtained from the application of new space technology. We have recently been reminded in the centenaries of Galileo, Kepler and Copernicus how the scientific revolution began with a revolution in knowledge of the solar system and we are now seeing clear indications that in the next 10 years, knowledge of the solar system and its origin will be revolutionalised.

The following are general references:

Proc. of the Apo11o 11 Lunar Science Conf. Supp1. 1, 1, 2, $\underline{3}$, Geochimica et Cosmochimica Acta, Pergamon Press, 1970.

Proc. 2nd Lunar Science Conf. Suppp1. 2, 1, 2, 3, Geochimica et Cosmochimica Acta, The MIT Press, 1971.

Proc. 3rd Lunar Science Conf. Supp1. 3, 1, 2, $\underline{3}$, Geochimica et Cosmochimica Acta, The MIT Press 1972.

Proc. 4th Lunar Science Conf. Supp1. 4, $1,2 \underline{2}, \underline{3}$, Geochimica et Cosmochimica Acta, Pergamon Press, 1973.

Proc. 5th Lunar Science Conf. Supp1. 5, $\underline{1}, \underline{2}, \underline{3}$, Geochimica et Cosmo- 
chimica Acta, Pergamon Press, 1974.

Proc. 6th Lunar Science Conf. Supp1. 6, 1, 2, 3, Geochimica et Cosmochimica Acta, Pergamon Press, 1975.

Proc. 7th Lunar Science Conf. Supp1. 7, 1, 2, 3, Geochimica et Cosmochimica Acta, Pergamon Press, 1976.

"The Moon - A New Appraisal from Space Missions and Laboratory Analyses" (Ed. S.K.Runcorn, G.M.Brown, G.Eglinton and H.C.Urey), Phil. Trans. Roy. Soc. A285, 1-600, 1977.

'Jupiter, Studies of the Interior, Atmosphere, Magnetosphere and Satellites"' (Ed.T.Gehre1s), University of Arizona Press, 1976. 